\title{
A IDENTIDADE INDÍGENA BRASILEIRA POR MEIO DAS IMAGENS DO LIVRO DIDÁTICO DE HISTÓRIA ${ }^{1}$
}

\author{
THE BRAZILIAN INDIGENOUS IDENTITY THROUGH IMAGES FROM HISTORY \\ TEXTBOOKS
}

Nádia Narcisa de Brito Santos²

\begin{abstract}
RESUMO: Este artigo analisa a identidade atribuída e veiculada acerca do índio e da índia brasileiros por meio das imagens - ilustrações, fotografias e pinturas - na coleção de livros didáticos de História do autor Alfredo Boulos Júnior (2016a, 2016b, 2016c), adotada no Programa Nacional de Livros Didáticos (PNLD) de 2018 para o Ensino Médio. Buscamos responder aos seguintes questionamentos: Como é representado o indígena brasileiro no livro didático por meio das imagens? Que/Quais identidade/s indígena/s é/são possível/eis vislumbrar por meio destas imagens? A escolha da referida coletânea se justifica por ser a mais adotada pelo PNLD de 2018, de acordo com os dados estatísticos disponibilizados pelo Fundo Nacional de Educação (FNDE), bem como é durante o ensino escolar que se constrói os conceitos sobre a índia e o índio, que são apresentados na escola, primordialmente, por meio do livro didático (CHOPPIN, 2004). O presente estudo utilizou o conceito de identidade de Stuart Hall (2006), a concepção de livro didático de Egil Borre Johnsen (1996) e Alain Choppin (2004), e a problematização de imagem de Peter Burke (2004). Percebemos que em todas as imagens desta coletânea, exceto uma, a índia e o índio são apresentados de cocar, sem vestimentas nos membros superiores e corpo pintado. Nesse contexto, as iconografias são genéricas, apresentando as etnias indígenas como se partilhassem da mesma identificação e cultura. Portanto, na coleção História, Sociedade \& Cidadania, as imagens da índia e do índio não os reconhecem em sua complexidade, sobressaltando-se elementos identitários que consideram "o índio genuíno", sem interferências de outras culturas, como o formador da nação brasileira, construindo e preservando uma identidade, nacionalidade, cultura e ideologia.
\end{abstract}

Palavras-Chave: Livro didático; Identidade indígena; Imagens.

ABSTRACT: This paper analyzes the identity assigned and tied to the Brazilian Indian through images - illustrations, photographs and paintings - in the collection of History

1 O presente trabalho é fruto de pesquisas desenvolvidas pela autora no Mestrado Acadêmico Interdisciplinar em História e Letras (MIHL), da Universidade Estadual do Ceará (UECE).

2 Cursa Mestrado Acadêmico Interdisciplinar em História e Letras pela Universidade Estadual do Ceará, na Faculdade de Educação, Ciências e Letras do Sertão Central, Campus de Quixadá (2018-2019), sob orientação da Professora Doutora Isaíde Bandeira da Silva e coorientação do Professor Doutor José Petrúcio de Farias Júnior. É bolsista pela Coordenação de Aperfeiçoamento de Pessoal de Nível Superior (CAPES). É especialista em História do Brasil pela Faculdade de Ciência e Educação do Caparaó (2017). Possuí graduação em História pela Universidade Federal do Piauí, Campus Senador Helvídio Nunes de Barros (CSHNB) (2016). E-mail: nadiabrito45@hotmail.com. 
textbooks by the author Alfredo Boulos Júnior, adopted in the Textbook National Program (Programa Nacional do Livro Didático - PNLD) of 2018 to high school. We aim to answer the following questions: How is the Brazilian Indian represented in the textbooks through images? What/Which identity/ies is/are possible to observe from those images? The choice of the collection mentioned above is justified by the fact that it was the most chosen by the PNLD of 2018, according to the statistical data provided by National Education Fund (Fundo Nacional de Educação - FNDE). It is also during the school teaching that the concept of the Indian is built, which is presented mainly through the textbook (CHOPPIN, 2004). The present study used the concept of identity from Stuart Hall (2006), the concept of textbook by Egil Borre Johnsen (1996) and Allain Chopin (2004), and the questioning of image by Peter Burke (2004). We observed that in every image of that collection, except one, the Indian is presented wearing a headdress, with no clothes in the upper limbs and with the body painted. In this context, the iconographies are generic, presenting the Indian ethnicities as if they shared the same identification and culture. Therefore, in the collection História, Sociedade e Cidadania (History, Society \& Citizenship), the images of the Indian do not represent their complexity, highlighting identity elements that consider the "genuine Indian", without interferences of other cultures, as the originator of Brazilian nation, building and preserving a national identity, nationality, culture and ideology.

Keywords: Textbook; Indigenous identity; Images.

\section{Introdução}

No caminhar do tempo o ser humano movimenta-se dinamicamente, criando e recriando práticas sociais e sentidos em seu viver. No frenesi dessa vida pós-moderna, conforme Hall (2006), dá-se o descentramento das identidades, ou seja, das posições do sujeito perante significados e valores na sociedade, em consonância ao seu contexto histórico-cultural. Posto isso, propomo-nos a problematizar a identidade atribuída e veiculada a índia e ao índio do Brasil no livro didático de História, por meio das imagens - ilustrações, fotografias e pinturas.

Tratamos dos povos indígenas especificando o gênero por acreditarmos que proferir apenas índio conota um carácter generalizante e de unicidade a uma etnia que possui um contexto histórico, cultural e social complexo, bem como o termo indica unicamente a figura masculina. Portanto, enfatizamos que não é nosso propósito discutir a relação texto-imagem, mas sim analisar a identidade atribuída e veiculada acerca da índia e do índio brasileiros por meio das iconografias da coleção de livros didáticos de História, de Alfredo Boulos Júnior 
(2016a, 2016b, 2016c), adotada no Programa Nacional de Livros Didático (PNLD) de 2018 para o Ensino Médio.

Em concordância com Peter Burke (2004), a imagem "[...] pode fornecer evidência para aspectos da realidade social que os textos passam por alto [...]" (BURKE, 2004, p. 37), isto é, a imagem testemunha o que não pode ser dito em palavras. Assim, buscamos responder aos seguintes questionamentos: Como são representados a índia e o índio brasileiros no livro didático por meio das imagens? Que/Quais identidade/s indígena/s é/são possível/eis vislumbrar por meio destas imagens?

A escolha dos livros didáticos de História da coleção História, Sociedade \& Cidadania, de Boulos Júnior (2016a, 2016b, 2016c), se justifica por ser a coletânea mais adotada pelo PNLD de 2018, de acordo com os dados estatísticos disponibilizados pelo Fundo Nacional de Educação (FNDE) ${ }^{3}$. A seleção dos livros do PNLD para o triênio 2018-2020, no âmbito do Ensino Médio, se fundamenta por serem analisados, comprados e distribuídos pelo Governo Federal, investimento que representa um importante capital das finanças públicas, bem como por esse referido material ser entregue para a maior parte dos estudantes brasileiros (CASSIANO, 2007).

Essa proposição torna-se relevante, tendo em vista que a mentalidade do educando acerca da sociedade e de sua identidade é constituída durante o ensino escolar, e nessa trajetória se constrói os conceitos a respeito dos povos indígenas, que são apresentados na escola, primordialmente, por meio do livro didático (CHOPPIN, 2004, p. 6). As imagens, para Peter Burke (2004), são formas de visualizar o outro e sua cultura, ou seja, de caracterizar identidades conferidas e difundidas acerca do outro, e, nesse contexto, acreditamos que por meio das iconografias propagadas no livro didático é possível visualizar uma identidade e/ou identidades indígenas.

Empregamos o conceito de identidade de Stuart Hall (2006), a concepção de livro didático de Egil Børre Johnsen (1996) e Alain Choppin (2004), e a

\footnotetext{
${ }^{3}$ A coleção História, Sociedade \& Cidadania teve os seguintes números de tiragens no $1^{\circ}, 2^{\circ}$ e $3^{\circ}$ anos do ensino médio, respectivamente: 657.825, 539.643 e 469.999 (FNDE - Serviço de Informação ao Cidadão).
} 
problematização de imagem de Peter Burke (2004). Estruturamos esse artigo em dois tópicos, a saber: $1^{\circ} \mathrm{O}$ livro didático, o item versa acerca da conceituação de livro didático e das mudanças no trato acerca da índia e do índio neste material. $2^{\circ}$ Existir e resistir: identidades indígenas, aborda a identidade atribuída e veiculada acerca dos povos indígenas do Brasil, por meio das imagens do livro didático de História na coleção referenciada.

\section{O livro didático}

Estudiosos do ensino de História e da Educação lançam múltiplos olhares acerca do livro didático, muitos deles maneiras díspares de enxergar este material. Etimologicamente a palavra livro tem origem do latim liber, usada para designar a parte da árvore entre a casca e o núcleo, utilizada como suporte para receber o texto (BELO, 2002). A gênese do termo didático deriva do grego didaktikós relativo à didática, campo de conhecimento da Pedagogia associado à arte de transmitir conhecimentos por meio do ensino (LIBÂNEO, 2006).

Ao discutir a respeito do conceito de livro didático, Johnsen (1996) realiza a distinção de três termos: livros didáticos, livros didáticos escolares e livros escolares. Livros didáticos, para o mesmo autor, remetem àqueles com sequência de instruções sobre algo, por exemplo: manual de instruções, livros de culinária. Livros didáticos escolares, mais conhecidos como livro didático, conforme Stray (1991 apud JOHNSEN, 1996), remetem a livros escritos e produzidos especificamente para o ensino; no Brasil são todos os livros recomendados pelo Ministério da Educação e Cultura (MEC) para uma determinada etapa da Educação Básica.

Livros escolares, segundo Choppin (1980 apud JOHNSEN, 1996), referemse a livros criados com o propósito de ajudar no ensino, porém não se caracterizam como didáticos. Um livro escolar pode ser ainda, por exemplo, um livro de Shakespeare, que não foi criado com o objetivo educacional, mas que em determinado momento converteu-se em livro escolar pelo seu uso no cotidiano escolar do docente e discente. Outros exemplos de livros escolares são: livros de histórias infantis, livros de colorir. Para esclarecer de maneira 
ilustrativa o conceito de livro didático empregado nesse artigo, observe o gráfico a seguir:

\section{Figura 1 - Conceito de Livro Didático}

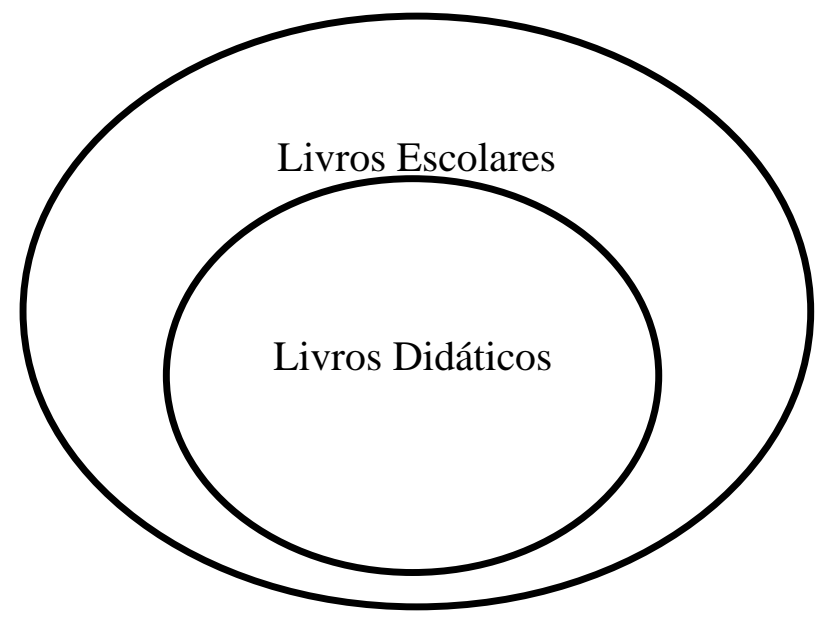

Fonte: Produção da autora (2018). Com base nos conceitos de livro didático de Johnsen (1996) e Choppin (1980 apud JOHNSEN, 1996)

Com base no presente gráfico, um livro didático - escolar - será sempre um livro escolar, porém nem todo livro escolar será livro didático. Os livros escolares são um conjunto maior de materiais utilizados no ensino, como dicionários, paradidáticos etc., e dentro desse agrupamento se encontra os livros didáticos designados pelo Estado para a Educação Básica. Este é o material didático que está em discussão nesse artigo, no qual utilizamos o termo livro didático.

O livro didático é a principal ferramenta utilizada por docentes e discentes no ensino básico. Em algumas escolas públicas do Brasil é o único recurso disponível (BITTENCOURT, 2008). Logo, este instrumento é ímpar na construção da imagem do outro, sobretudo de povos indígenas (TELLES apud GRUPIONI, 1995). Acreditamos que ao projetar um olhar sobre o outro, o livro didático é atribuidor e veiculador de uma identidade indígena, em virtude da tomada de posição acerca do que constitui o referido sujeito, a partir de uma construção histórica.

No eterno devir da sociedade pós-moderna, Hall (2006) pondera que a dinamicidade do ser forma-o e transforma-o continuamente, partindo de 
interpelações e representações delineadas. Ainda segundo o mesmo autor, o arranjo posicional de um indivíduo projeta múltiplas identidades que variam em cada contexto e local, ou seja, ocorre descentramentos identitários. Conjecturamos que tais deslocamentos podem aparecer nas sutilezas das imagens e, na análise em questão, naquelas que versam sobre os povos indígenas brasileiros no livro didático, uma vez que são testemunhas oculares das práticas sociais, cultura e identidade dos indivíduos (BURKE, 2004).

Nesse sentido, o livro didático é portador de preceitos, cultura e ideologia, produzindo significados e valores que permeiam a sociedade na obra e a obra na sociedade (BITTENCOURT, 2008). Atribui-se a este material, conforme Choppin (2004), a função ideológica e cultural em que existe uma relação de simbiose, na qual o social determina o que será proposto no livro didático e o mesmo determina o corpus social. Isso ocorre uma vez que um conjunto de educadores e líderes políticos definem um currículo da educação básica, que tem uma de suas formas em livro didático ${ }^{4}$, e este material contribui com discentes e docentes na formulação de conceitos e visões sobre diversos assuntos e sujeitos. Assim confirma Johnsen (1996, p. 24):

Los libros de texto son um tipo de literatura compleja colocada y compilada por varias partes interesadas (especialistas, autores, editores, autoridades), y tienen la intención de servir a diversos grupos de usuarios (maestros, estudiantes/alumno, padres).

Sacristán e Goméz (1988) ressalvam que, entre o que é prescrito no currículo e o aplicado, exige uma elaboração intermediária desse currículo, que aparece nos materiais pedagógicos, e em especial no livro didático. Sendo assim, "os problemas e soluções encontrados pelo empresariado do setor editorial dos livros didáticos repercutem no mundo escolar." (CASSIANO, 2007, p. 5). Deste modo, as equipes que constroem o livro didático são produtoras de uma cultura escolar aceita e legitimada pelo Estado por meio do PNLD.

\footnotetext{
${ }^{4}$ Sacristán e Goméz (1988, p. 139) evidenciam o currículo como um processo, podendo ser dividido em partes que se interligam, sendo elas: a) currículo prescrito e regulamentado, composto pelas decisões políticas e administrativas; b) currículo planejado, constitui a elaboração de materiais e guias; c) currículo organizado, engloba a estrutura organizativa da escola; d) currículo em ação, representa as práticas e tarefas desenvolvidas em sala de aula; e) currículo avaliado, que constitui os processos avaliativos da aprendizagem discente.
} 
O material didático em questão torna-se, conforme Bittencourt (2008), em muitos espaços escolares, um material de preparação de aulas em todos os níveis escolares, além de ser empregado como suporte de planejamento diário e letivo na sistematização de conteúdos e na construção de atividades. Para Choppin (2004), o livro didático possui função referencial, pois "[...] constitui o suporte privilegiado dos conteúdos educativos, o depositário dos conhecimentos, técnicas ou habilidades que um grupo social acredita que seja necessário transmitir às novas gerações." (CHOPPIN, 2004, p. 553).

Em tal cenário o livro didático detém, em conformidade com Choppin (2004), natureza complexa, que de acordo com Stray (1993), "se situa no cruzamento da cultura, da pedagogia, da produção editorial e da sociedade". (STRAY apud CHOPPIN, 2004, p. 563). Consequentemente, para nós historiadores, ele assume função depositária enquanto documento que comporta em si outros documentos, dentre eles as imagens, fonte fecunda acerca da cultura escolar e do ensino de História (CHOPPIN, 2004).

Em vista disso, a abordagem identitária do indígena no recurso em foco sofreu os percalços da historiografia brasileira que, segundo Cunha (1992), no decorrer do século XVIII até meados do XIX, tivera enfoque no extermínio ou na ideia de civilizar o indígena. Somente em escrita posterior passou-se a analisar a História do Brasil pelas lentes dos seus primeiros habitantes. Tais mudanças incidiram sobre a apresentação da índia e do índio no livro didático de História.

A Constituição de 1988 garante a presença de discussões acerca da diversidade brasileira no ambiente educacional. A Lei de Diretrizes e Bases (LDB) n 9.394 de 1996, de modo específico, assegura que o ensino deverá considerar as contribuições das matrizes africanas, indígenas e europeias. Retratar a história e cultura indígena no âmbito da sala de aula passou a ser obrigatório a partir de 2008 com a Lei $n^{\circ} 11.645$, que alterou a LDB e sistematizou em forma de conteúdo a presença indígena por meio do artigo 26-A $\S 1^{\circ}$, o que passou a determinar os temas acerca desse sujeito histórico no material didático.

$\S 1$ ㅇ O conteúdo programático a que se refere este artigo incluirá diversos aspectos da história e da cultura que caracterizam a formação da população brasileira, a partir desses dois grupos 
étnicos, tais como o estudo da história da África e dos africanos, a luta dos negros e dos povos indígenas no Brasil, a cultura negra e indígena brasileira e o negro e o índio na formação da sociedade nacional, resgatando as suas contribuições nas áreas social, econômica e política, pertinentes à história do Brasil (BRASIL, 2008, p. 1).

Tais conteúdos são obrigatórios em todo o currículo escolar, mas em especial nas disciplinas de História, Educação Artística e Literatura. No que concerne à elaboração dos livros didáticos para as escolas públicas de nível médio do Brasil, o órgão responsável é o MEC por meio do PNLD. Este é um Programa do Governo Federal brasileiro que avalia e disponibiliza livros didáticos de maneira sistemática, regular e gratuita às escolas públicas da Educação Básica nas etapas de Ensino Fundamental I e II e Ensino Médio, tendo assim, como única exceção, os discentes da educação infantil. O Programa atende às instituições das redes federais, estaduais, municipais e distrital, assim como escolas comunitárias, confessionais ou filantrópicas sem fins lucrativos e conveniadas com o Poder Público. O objetivo central do PNLD é oferecer a discentes e docentes que pertencem às escolas que se encaixam no perfil descrito, livros didáticos de qualidade para o apoio do ensino-aprendizagem nos estudos formais nas etapas mencionadas (CASSIANO, 2007).

O PNLD entrega à sociedade um guia trienal que a partir de 2019 passou a ser quadrienal, com a relação dos livros a serem escolhidos pelos docentes das escolas. De acordo com edital de convocação para o processo de inscrição e avaliação de obras didáticas do PNLD de 2018, estão dentre os critérios de avaliação, a promoção positiva da cultura e história dos povos indígenas brasileiros, em vista a considerar a participação de tais sujeitos no processo histórico da construção do Brasil. Nesse sentido, analisamos no tópico seguinte a identidade indígena nas imagens da coletânea de História mais adotada pelo PNLD de 2018. 


\section{Existir e resistir: identidades indígenas}

Ao discorrer sobre identidade, Hall (2006) compreende esse conceito como o posicionamento do sujeito diante da sociedade, o qual leva em consideração o contexto cultural, social e histórico que se encontra inserido, bem como o arranjo posicional pode ser modificado, o que Hall (2006) denomina de deslocamentos identitários, que ocorrem conforme as situações e contextos. O mesmo autor afirma que nossa identidade também é composta do modo como imaginamos sermos vistos pelos outros.

A imagem, conforme Burke (2004), é testemunha ocular que presentifica de modo visual a identidade, cultura e práticas sociais do ser humano. Ela torna-se evidência da História, e como tal deve passar pelo mesmo crivo que as fontes escritas. Como documento que comporta outros documentos, o livro didático é rico em imagens, do qual captar algo destas é perceber aquilo que autores, editores, fotógrafos e pintores nem mesmo imaginavam transmitir, é ler nas "entrelinhas" de um material complexo (CHOPPIN, 2004).

Como traduzir o que se vê em palavras? Esse é um dos desafios quando se emprega imagens como fontes. Consideramos que as imagens contam Histórias que podem ser lidas pelo olhar. Para Burke (2004), elas foram feitas para comunicar no silêncio do seu testemunho. De acordo com Foucault, "o que vemos nunca está no que dizemos" (FOUCAULT apud BURKE, 2004, p. 43). A imagem é como uma fonte jorrante de água: nunca se esgota. Problematizar imagens é caminhar pelas águas de uma torrente que a cada nova interpretação brota uma nova gota.

Apresentamos a seguir uma lista com as iconografias da índia e do índio brasileiros encontradas na coleção História, Sociedade \& Cidadania, de Alfredo Boulos Júnior (2016a, 2016b, 2016c), enviada para avaliação do PNLD em 2016 e a mais adotada pelo mesmo Programa em 2018. Na tabela em questão temse: o ano letivo do livro didático, a classificação da imagem, a página e seção, a posição e a legenda da imagem no material. 
Tabela 1 - 0 indígena brasileiro no livro didático de História, coleção História, Sociedade \& Cidadania do PNLD de 2018.

\begin{tabular}{|c|c|c|c|c|c|}
\hline $\begin{array}{c}\text { Ano } \\
\text { letivo }\end{array}$ & $\begin{array}{l}\text { Classificação } \\
\text { da imagem }\end{array}$ & $\begin{array}{c}\text { Página } / \mathbf{S} \\
0\end{array}$ & Seçã & Posição & Legenda \\
\hline $1^{\circ} \mathrm{Ano}$ & Pintura & $\begin{array}{l}\text { Página } \\
\text { seção } \\
\text { Cruzando } \\
\text { Fontes. }\end{array}$ & 261, & $\begin{array}{l}\text { Parte } \\
\text { superior da } \\
\text { página }\end{array}$ & Não há legenda. \\
\hline $2^{\circ}$ Ano & Fotografia & $\begin{array}{l}\text { Sumário } \\
\text { livro. }\end{array}$ & do & $\begin{array}{l}\text { Final } \\
\text { página }\end{array}$ & Não há legenda. \\
\hline $2^{\circ}$ Ano & Fotografia & $\begin{array}{l}\text { Página } \\
\text { abertura } \\
\text { capítulo } 1 .\end{array}$ & $\begin{array}{r}12 \\
\text { do }\end{array}$ & $\begin{array}{l}\text { Centro } \\
\text { página. }\end{array}$ & $\begin{array}{l}\text { Meninos guaranis, São Paulo } \\
\text { (SP), } 2011 . \\
\text { Menina Kaipó, Alto Paraíse de } \\
\text { Goiás (GO), } 2014 .\end{array}$ \\
\hline $2^{\circ}$ Ano & Pintura & $\begin{array}{l}\text { Página } \\
\text { capítulo } 1 .\end{array}$ & 22 & $\begin{array}{l}\text { Final da } \\
\text { página lado } \\
\text { esquerdo. }\end{array}$ & Feita por Francis Castelnau. \\
\hline $2^{\circ}$ Ano & Pintura & $\begin{array}{l}\text { Página } \\
\text { capítulo } 1 .\end{array}$ & 22 & $\begin{array}{l}\text { Final da } \\
\text { página, lado } \\
\text { direito. }\end{array}$ & Feita por Hércules Florence. \\
\hline $2^{\circ}$ Ano & Fotografia & $\begin{array}{l}\text { Página } \\
\text { capítulo } 1 .\end{array}$ & 24 & $\begin{array}{l}\text { Centro } \\
\text { página. }\end{array}$ & $\begin{array}{l}\text { Arte plumária Kayapó de } \\
\text { 2008. }\end{array}$ \\
\hline $2^{\circ}$ Ano & Fotografia & $\begin{array}{l}\text { Página } \\
\text { capítulo } 1 .\end{array}$ & 24 & $\begin{array}{l}\text { Centro } \\
\text { página. }\end{array}$ & $\begin{array}{l}\text { Pintura corporal no rosto de } \\
\text { uma menina Kayapó da } \\
\text { aldeia Moykarakô, São Felix } \\
\text { do Xingu (PA), } 2015 \text {. } \\
\text { Fot. 1: construção de oca, }\end{array}$ \\
\hline $2^{\circ}$ Ano & Fotografia & $\begin{array}{l}\text { Página } \\
\text { capítulo } 1 .\end{array}$ & 25 & $\begin{array}{l}\text { Parte } \\
\text { superior da } \\
\text { página. }\end{array}$ & $\begin{array}{l}\text { Aldeia Kamayurá, Parque do } \\
\text { Xingu, Mato Grosso, } 2014 . \\
\text { Fot. 2: colheita da mandioca, } \\
\text { povo indígena barasano, } \\
\text { Manaus (AM), 2014. Fot. 3: } \\
\text { mulher Kalapalo preparando } \\
\text { beiju, Aldeia Ailha, também } \\
\text { no Parque do Xingu, } 2011 .\end{array}$ \\
\hline $2^{\circ}$ Ano & Fotografia & $\begin{array}{l}\text { Página } \\
\text { capítulo } 1 .\end{array}$ & 27, & $\begin{array}{l}\text { Canto direito } \\
\text { da página. }\end{array}$ & $\begin{array}{l}\text { Cacique Tafukumã, da nação } \\
\text { Kalapalo, na Aldeia Ailha, em } \\
\text { Querência (MT), } 2009 .\end{array}$ \\
\hline $2^{\circ}$ Ano & Fotografia & $\begin{array}{l}\text { Página } \\
\text { capítulo } 1 .\end{array}$ & 28 & $\begin{array}{l}\text { Final } \\
\text { página. }\end{array}$ & $\begin{array}{l}\text { Escola indígena com } \\
\text { estudantes do povo saterê- } \\
\text { maué, em Manaus (AM), } \\
2014 \text {. }\end{array}$ \\
\hline $2^{\circ}$ Ano & Ilustração & $\begin{array}{l}\text { Página } \\
\text { capítulo } 3 .\end{array}$ & 53 & $\begin{array}{l}\text { Final } \\
\text { página. }\end{array}$ & $\begin{array}{l}\text { Representação de } 1556 \text { do } \\
\text { escambo entre portugueses e }\end{array}$ \\
\hline
\end{tabular}




\begin{tabular}{|c|c|c|c|c|c|}
\hline & & & & & indígenas. \\
\hline $2^{\circ}$ Ano & Ilustração & $\begin{array}{l}\text { Página } \\
\text { seção } \\
\text { dialogando }\end{array}$ & 56 & $\begin{array}{l}\text { Canto } \\
\text { esquerdo da } \\
\text { página. }\end{array}$ & Não há legenda. \\
\hline $2^{\circ}$ Ano & Fotografia & $\begin{array}{l}\text { Página } \\
\text { seção } \\
\text { cidadão. }\end{array}$ & $\begin{array}{l}75 \\
\text { você }\end{array}$ & $\begin{array}{l}\text { Canto direito } \\
\text { da página. }\end{array}$ & $\begin{array}{l}\text { Criança ianomâmi } \\
\text { carregando cacho de } \\
\text { pupunha madura na Aldeia } \\
\text { do Kona, Santa Isabel do Rio } \\
\text { Negro (AM), 2011. }\end{array}$ \\
\hline $2^{\circ}$ Ano & Ilustração & $\begin{array}{l}\text { Página } \\
\text { capítulo } 5 .\end{array}$ & 99 & $\begin{array}{l}\text { Canto direito } \\
\text { da página. }\end{array}$ & $\begin{array}{l}\text { Acampamento bandeirante } \\
\text { para plantio de roças, } \\
\text { aquarela de Ivan Washt } \\
\text { Rodrigues. }\end{array}$ \\
\hline $2^{\circ}$ Ano & Fotografia & $\begin{array}{l}\text { Página } \\
\text { seção } \\
\text { Refletir. }\end{array}$ & $\begin{array}{l}\text { 100, } \\
\text { Para }\end{array}$ & $\begin{array}{l}\text { Canto } \\
\text { esquerdo da } \\
\text { página. }\end{array}$ & $\begin{array}{l}\text { Criança Pataxó da aldeia } \\
\text { Velha, Caraíva (BA), } 2014 .\end{array}$ \\
\hline $2^{\circ}$ Ano & Fotografia & $\begin{array}{l}\text { Página } \\
\text { seção } \\
\text { cidadão. }\end{array}$ & $\begin{array}{l}135, \\
\text { Você }\end{array}$ & $\begin{array}{l}\text { Canto direito } \\
\text { da página. }\end{array}$ & $\begin{array}{l}\text { Arte plumária Karajá, São } \\
\text { Paulo (SP), } 2008 .\end{array}$ \\
\hline $2^{\circ}$ Ano & Pintura & $\begin{array}{l}\text { Página } \\
\text { capítulo } 10\end{array}$ & $\begin{array}{l}207, \\
0 .\end{array}$ & $\begin{array}{l}\text { Canto direito } \\
\text { da página. }\end{array}$ & $\begin{array}{l}\text { José Bonifácio a fundação da } \\
\text { pátria, tela de Eduardo de } \\
\text { Sá. }\end{array}$ \\
\hline $3^{\circ}$ Ano & Fotografia & $\begin{array}{l}\text { Página } \\
\text { abertura } \\
\text { Unidade } \\
\text { intitulada } \\
\text { Movimento } \\
\text { sociais. }\end{array}$ & $\begin{array}{r}144 \\
\text { da } \\
3 \\
\text { de } \\
\text { os }\end{array}$ & $\begin{array}{l}\text { Final } \\
\text { página. }\end{array}$ & $\begin{array}{l}\text { Indígenas de várias etnias } \\
\text { em Brasília (DF) em } \\
\text { manifestação contra a PEC } \\
215 \text {, que transfere para o } \\
\text { Congresso a palavra final } \\
\text { sobre a demarcação de } \\
\text { reservas, em } 3 \text { de outubro de } \\
2013 \text {. }\end{array}$ \\
\hline $3^{\circ}$ Ano & Fotografia & $\begin{array}{l}\text { Página } \\
\text { texto } \\
\text { principal. }\end{array}$ & 221, & $\begin{array}{l}\text { Canto direito } \\
\text { da página. }\end{array}$ & $\begin{array}{l}\text { Fotografia de } 1988 \text {, em } \\
\text { Brasília (DF), mostra a } \\
\text { presença de índios em } \\
\text { Sessão da Assembleia } \\
\text { Constituinte, que reconheceu } \\
\text { importantes direitos dos } \\
\text { povos indígenas. }\end{array}$ \\
\hline
\end{tabular}

Fonte: Produção da autora (2018). Com base nas iconografias da coleção História, Sociedade \& Cidadania do PNLD (2016a, 2016b, 2016c).

A coletânea de Boulos Júnior (2016a, 2016b, 2016c) é composta de três livros didáticos de História, um para cada ano do Ensino Médio. Em toda a coleção contabilizamos 19 (dezenove) imagens entre ilustrações, pinturas e 
fotografias. Desse total, encontramos a presença de 17 (dezessete) índios e 12 (doze) índias; estas, por sua vez, em maioria eram crianças. No que concerne ao posicionamento destinado ao indígena nesse recurso pedagógico, 8 (oito) imagens localizam-se no canto direito ou esquerdo, 6 (seis) no final da página, 3 (três) ao centro e 2 (duas) na parte superior das páginas. Notamos que a localização das imagens acerca da índia e do índio pertence, preponderantemente, às dobras e ao final das páginas. Apenas 5 (cinco) imagens aparecem em seções dos livros didáticos. As seções são espaços que o autor destina para discutir e/ou apresentar questões sobre temas que se relacionam com o capítulo em debate. O fato de haver imagens em seções do livro, nos cantos e no final das páginas, em muitos casos, implicará na não utilização ou subutilização das mesmas, uma vez que, conforme Bittencourt (2008), frequentemente o professor utiliza somente o texto principal do livro.

A mulher índia, quando representada, estava relacionada aos afazeres domésticos como, por exemplo, no ato de preparar alimentos. Compreendemos a presença da mulher índia como aspecto novo, uma vez que nos materiais didáticos destinados à Educação Básica do século $X X$, sua presença era ínfima (GRUPIONI, 1995), embora ainda esteja associada às atividades do lar, o que desconsidera a pluralidade dos grupos étnicos indígenas e dos papéis sociais ${ }^{5}$. 0 elemento dominante ainda prepondera na apresentação veemente do homem índio neste material; o mesmo é retratado como cacique, guerreiro, construtor.

\footnotetext{
5 Podemos citar como exemplo a comunidade indígena Jenipapó-Kanidé que fica em Aquiraz, Estado do Ceará, e que tem por líder cacique uma mulher, a cacique Pequena. Ver mais: MARTINS (2012).
} 
Fotografia 1 - (1) Construção de oca, Aldeia Kamayará, Parque do Xingu, Mato Grosso, 2014. (2) colheita da mandioca, povo indígena barasano, Manaus (AM), 2014. (3) mulher Kalapalo preparando beiju, Aldeia Aiha, também no Parque Xingu, 2011.
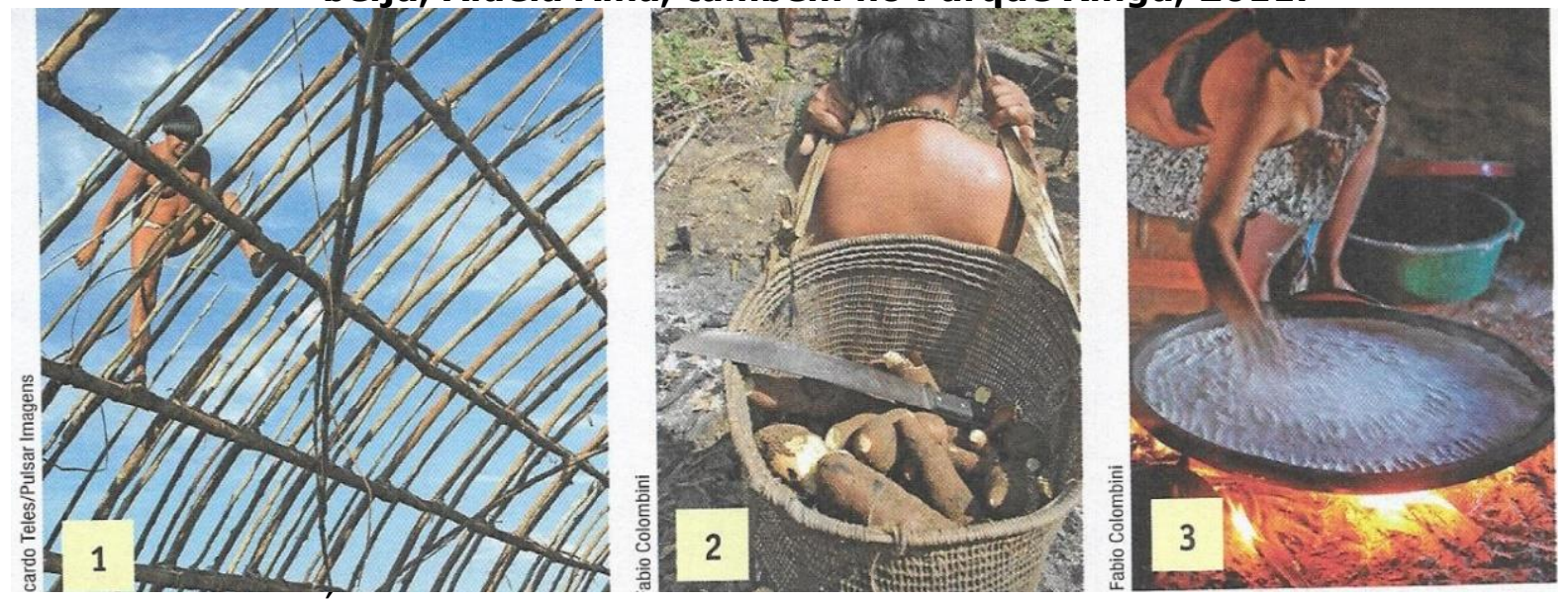

Fonte: BOULOS JÚNIOR (2016b, p. 22).

Um dos propósitos das imagens é retratar o cotidiano e os hábitos sociais (BURKE, 2004). A fotografia acima apresenta três visualizações do indígena; a primeira e a terceira retratam, respectivamente, um índio e uma índia, ambos do Parque Xingu, Mato Grosso, e a segunda, uma índia na aldeia de Manaus, Amazonas, todas cenas capturas pelas lentes do século XXI. O índio é retratado construindo o que parece ser uma oca. Este tipo de habitação feita de galhos e troncos de árvores é comum na vivência indígena, porém, esta é a única imagem da coleção que remete à residência dessa etnia, o que passa a ideia de que, na contemporaneidade, índias e índios vivem no mesmo tipo de casa, ignorando que hodiernamente em muitas aldeias/comunidades os indígenas vivem em casas feitas de tijolos e cimento.

Na sequência das imagens, uma índia é representada colhendo mandioca e logo em seguida outra é retratada fazendo beiju. A sucessão dos acontecimentos das imagens permite vislumbrar os locais de cada sujeito e seu papel social na aldeia/comunidade a que pertence, mas de todo modo limita a apenas uma visão da atuação da índia na complexidade da aldeia/comunidade. A imagem demonstra a presença indígena na contemporaneidade, embora restrita à região Norte e Centro-Oeste do Brasil, desconsiderando a pluralidade de grupos étnicos 
indígenas existente no País ${ }^{6}$. Seria interessante que o discente tivesse uma visualização da presença indígena em todas as regiões do Brasil, bem como, nesse contexto, o livro poderia realizar um paralelo com a geografia, o que cumpriria um dos critérios do edital do PNLD/2018, que discorre sobre a interdisciplinaridade entre as matérias (BRASIL, 2015).

Nesse contexto, entendemos que o livro didático tornou-se um mecanismo de reprodução e manutenção da forma dominante de visualizar o "índio brasileiro", a ideia de identificar e representar povos indígenas como únicos. A própria terminologia índio já se incube disso, a qual perpetua no imaginário brasileiro e provoca a noção de que toda índia e índio são da mesma etnia, falam a mesma língua ou que habitam apenas um lugar. Consideramos haver uma imagem social do que é ser indígena e de sua identidade apartada da complexidade, fluidez e dinamicidade das ações e práticas sociais de tal indivíduo. Para Hall (2006), uma forma de unificar "[...] tem sido a de representá-las [sujeito e sua cultura] como a expressão da cultura subjacente de "um único povo'." (HALL, 2006, p. 62). Nesse caso, a unificação da índia e do índio em um único povo indígena.

No livro do $1^{\circ}$ ano do Ensino Médio tem-se apenas uma imagem que versa acerca da índia e do índio; a ilustração foi posicionada no final do material, em uma seção localizada no penúltimo capítulo.

${ }^{6}$ Ver dados da presença indígena no Brasil (IBGE, 2018). 
Ilustração 1 - A primeira missa no Brasil, de Victor Meirelles, 1860.

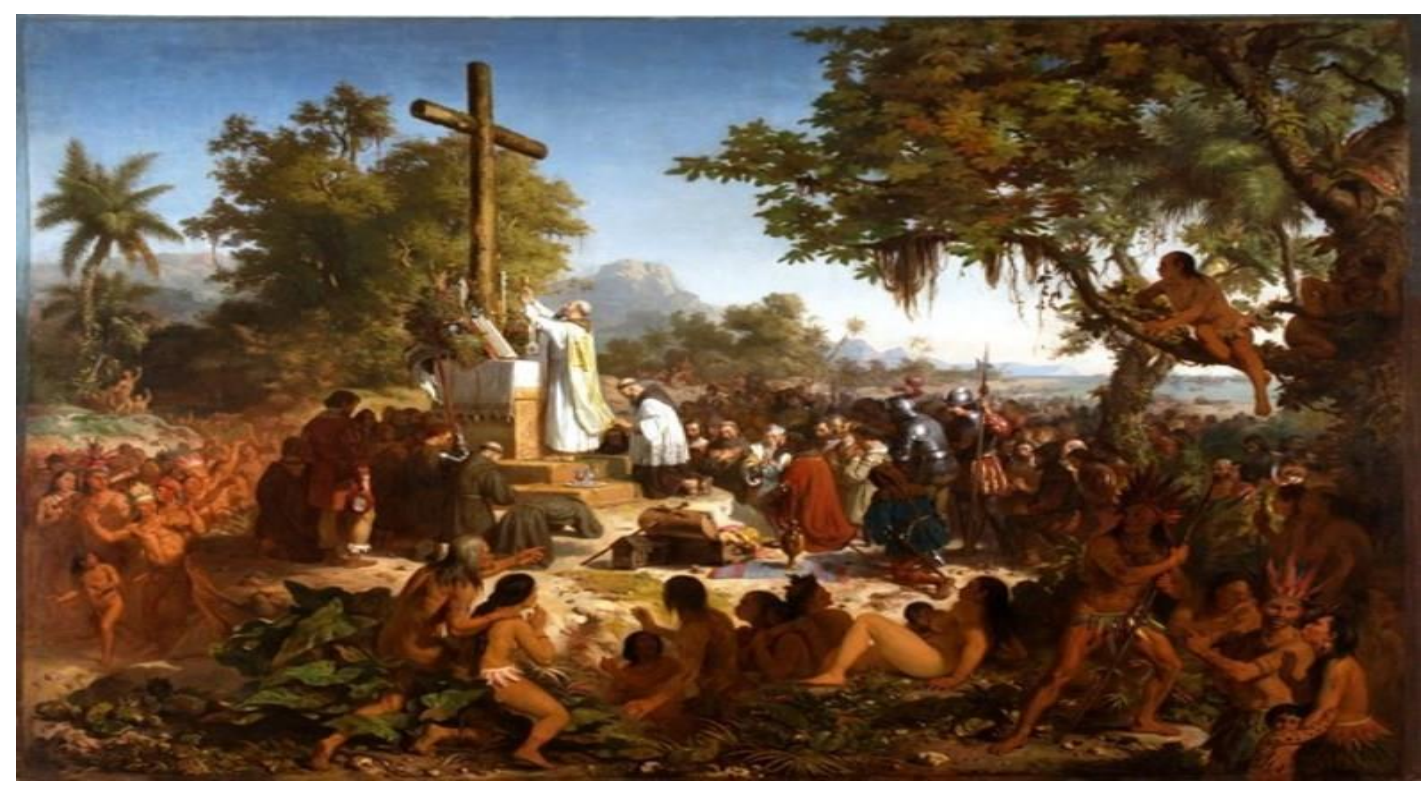

Fonte: BOULOS JÚNIOR (2016a, p. 161).

Na representação da tela $A$ primeira missa no Brasil, por Victor Meirelles, no ano de 1860, índias e índios parecem curiosos com o que os homens brancos realizavam. Na pintura em questão, são retratados seminus, pintados, com cocar e uma pequena vestimenta de penas que cobre suas genitálias; concepção romântica e de exaltação ao nacionalismo, característica do século XIX.

O maior número de imagens a respeito dos povos indígenas fora encontrado no livro didático do segundo ano. No capítulo 1 (um), intitulado de América indígena, Boulos Júnior (2016b), retrata o índio em toda a América, ressaltando a priori os povos maias, astecas, incas e na sequência, a índia e o índio brasileiros. Posteriormente, este sujeito aparece no capítulo 3 (três), que tem por título A América portuguesa e a presença holandesa, no qual é possível visualizar uma ilustração em que índios retiram recursos da natureza e entregaos para o português. A partir de então, os povos indígenas somente aparecem em seções, sendo apresentados colhendo alimentos ou pintando o corpo. Assim, após retratar a índia e o índio na colonização das terras brasílicas, tem-se esse sujeito no cenário do século XIX. Veja a imagem a seguir: 


\section{Ilustração 2 - 0 índio do Brasil no século XIX}
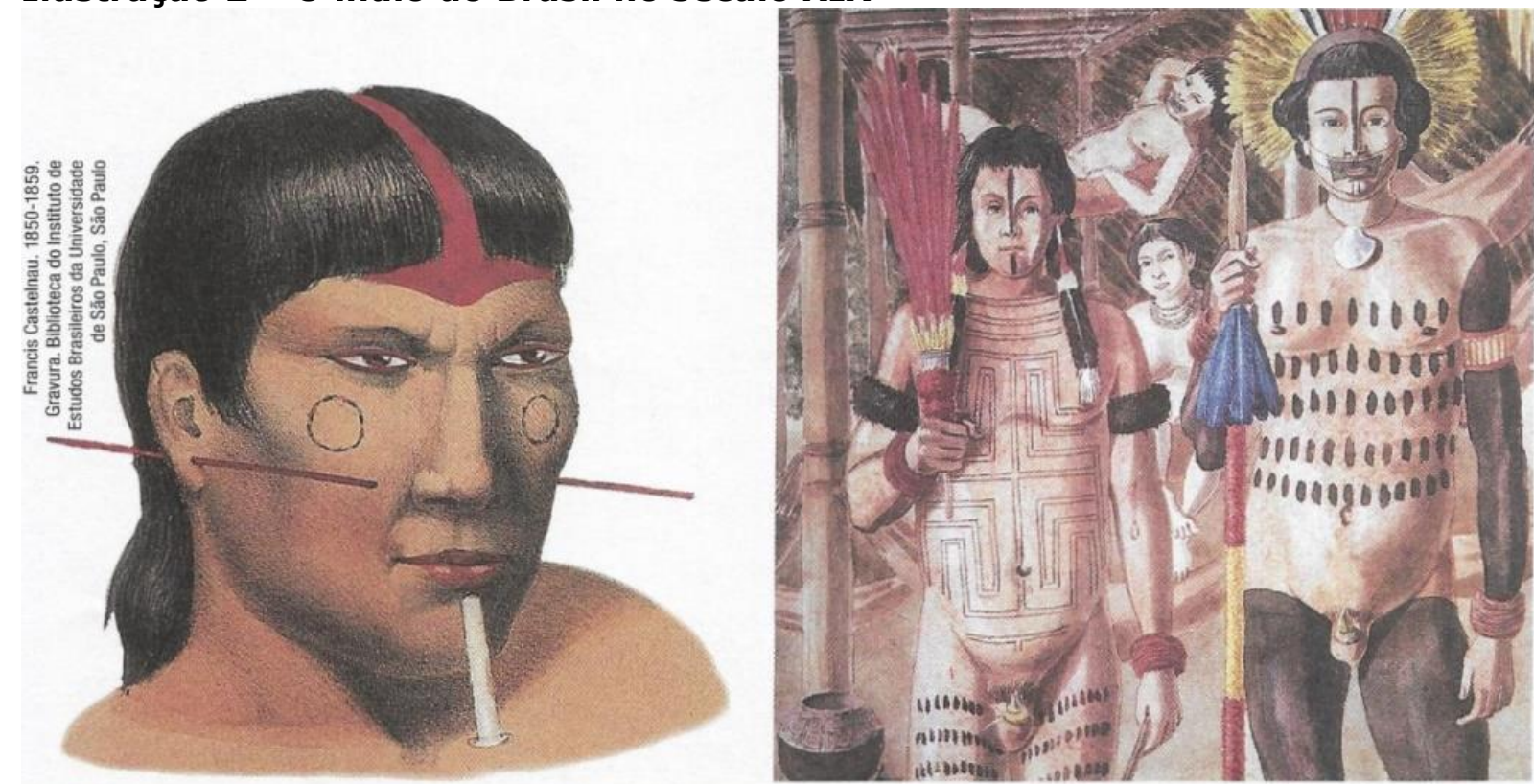

Fonte: BOULOS JÚNIOR (2016b, p. 22).

"Eram pardos, todos nus, sem coisa alguma que lhes cobrisse suas vergonhas. Nas mãos traziam arcos com suas setas." (CAMINHA, 2020, p.1). Corpos pintados, cocar e adornos pelo corpo, assim são retratados a índia e o índio no século XIX, como descrito por Pero Vaz de Caminha em carta ao chegar às terras brasílicas no século XV. Notamos a predominância dos marcos europeus em detrimento aos indígenas. "Alie-se a isto o fato de o livro didático constituirse numa autoridade, tanto em sala de aula quanto no universo letrado do aluno. É o livro didático que mostra, com textos e imagens, como a sociedade chegou a ser o que é, como ela se constituiu e se transformou até chegar nos dias atuais" (TELLES apud GRUPUONI, 1995, p. 486). Burke (2004) salienta que em muitas vezes tomamos a imagem como representações específicas e instantâneas de como o sujeito era em um momento específico. Para ele:

É necessário resistirmos a esse impulso por diversas razões. Em primeiro lugar, o retrato pintado é um gênero artístico que, como outros gêneros, é composto de acordo com um sistema de convenções que muda lentamente com o tempo. As posturas e gestos dos modelos e os acessórios e objetos representados à sua 
volta seguem um padrão e estão frequentemente carregados de sentido simbólico (BURKE, 2004, p. 31).

Os aspectos ilustrativos do livro didático são os mais chamativos para o discente. Conforme Choppin (2004), o aluno constrói sua memória acerca dos sujeitos históricos ao longo do ensino escolar. Nesse sentido, a maneira como a índia e o índio são representados nas imagens leva-o a construir um retrato que ficará em sua memória.

No livro do $3^{\circ}$ ano, a índia e o índio aparecem em uma abertura de unidade que é intitulada de Movimentos sociais, e em um capítulo denominado Regime militar, no tópico Constituição. A natureza emergente de tais sujeitos consiste quando estes aparecem em um tópico que versa a respeito da Constituição de 1988, visto que em materiais didáticos anteriores, em especial do século XX, sua apresentação se restringia ao passado (GRUPIONI, 1995). Entretanto, índia e índio ainda precisam estar de cocar, sem camisa e pintar o corpo para serem reconhecidos como "índio". As imagens fazem uma projeção do "índio genuíno", com cultura identitária estática, pura, na qual para ser índia ou índio é necessário estar caracterizado como "índio". Observe as imagens:

\section{Fotografia 2 - Indígenas de várias etnias em Brasília (DF), em manifestação}

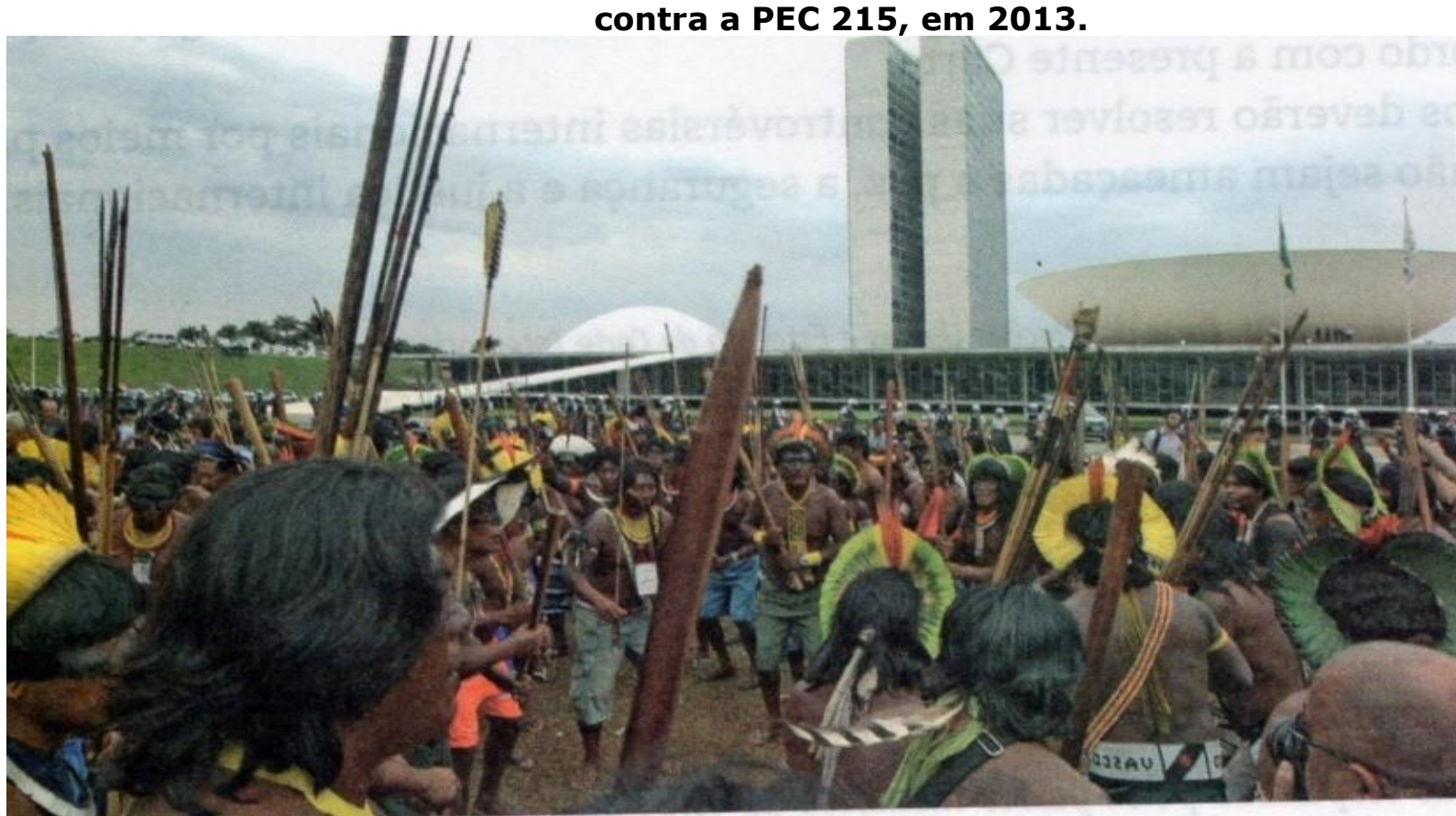

Fonte: BOULOS JÚNIOR (2016c, p. 144). 
$\mathrm{Na}$ fotografia acima temos indígenas de várias etnias que protestam em frente ao Congresso Nacional, em Brasília, contra a Proposta de Ementa Constitucional (PEC) n 215 de 2000, a qual transfere a competência da União na demarcação das terras indígenas e quilombolas para o Congresso Nacional, bem como propõe a revisão das terras já demarcadas e novos critérios e procedimentos para a demarcação destas áreas, que passariam a serem regulamentadas por lei, e não por decreto. Os sujeitos da imagem estão vestidos com bermudas, cocar, pintura corporal, sem camisa e tacapes - arma indígena. A imagem supõe que os sujeitos estavam em movimento, como se realizassem uma dança, e esta servisse de reafirmação de sua cultura e protesto contra a referida emenda.

Fotografia 3 - Indígenas em Assembleia Constituinte em Brasília (DF), 1988.

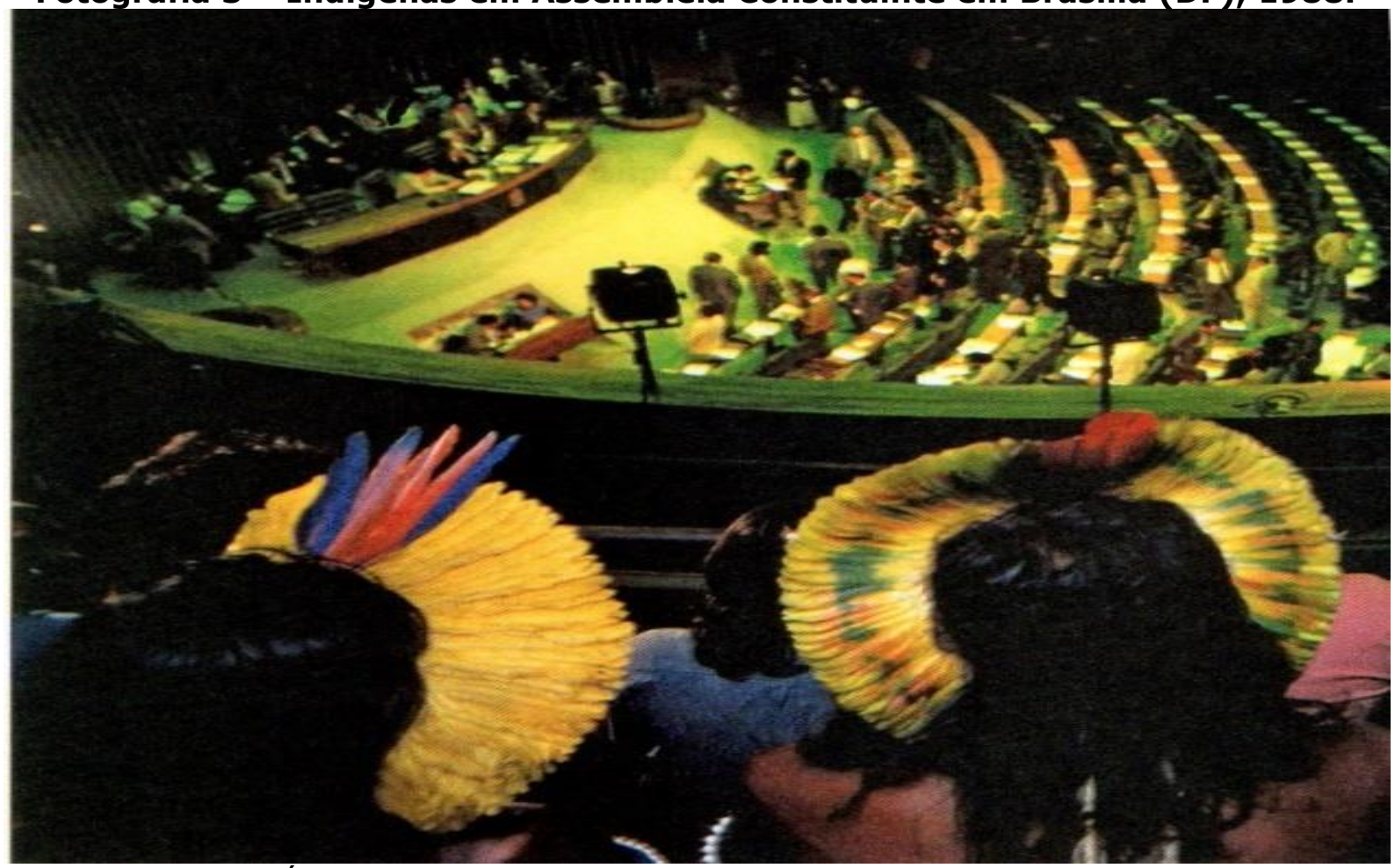

Fonte: BOULOS JÚNIOR (2016c, p. 221).

Na fotografia acima é possível visualizar dois índios assistindo a uma assembleia em Brasília, Distrito Federal. A imagem foi capturada de um ângulo alto, no qual tais sujeitos aparecem em primeiro plano com destaque para seus 
cocares, atentos ao que era discutido pelos homens da tribuna. Embora tais sujeitos estejam em Assembleia Constituinte, a imagem sugere que os indígenas são meros expectadores no teatro do poder, mas que, também, afirmam sua existência pela presença na sessão.

Até o presente momento, as imagens da coleção em análise representam índias e índios sempre com cocar, pintura no corpo e, alguns, com vestimentas a partir dos membros inferiores. Será somente isso que identifica esses indivíduos? Apenas uma imagem em toda a coleção não apresenta o indígena com essas características; a fotografia pertence ao livro didático do segundo ano do Ensino Médio.

\section{Fotografia 4 - Escola indígena com estudantes do povo saterê-maué, em} Manaus (AM), 2014.

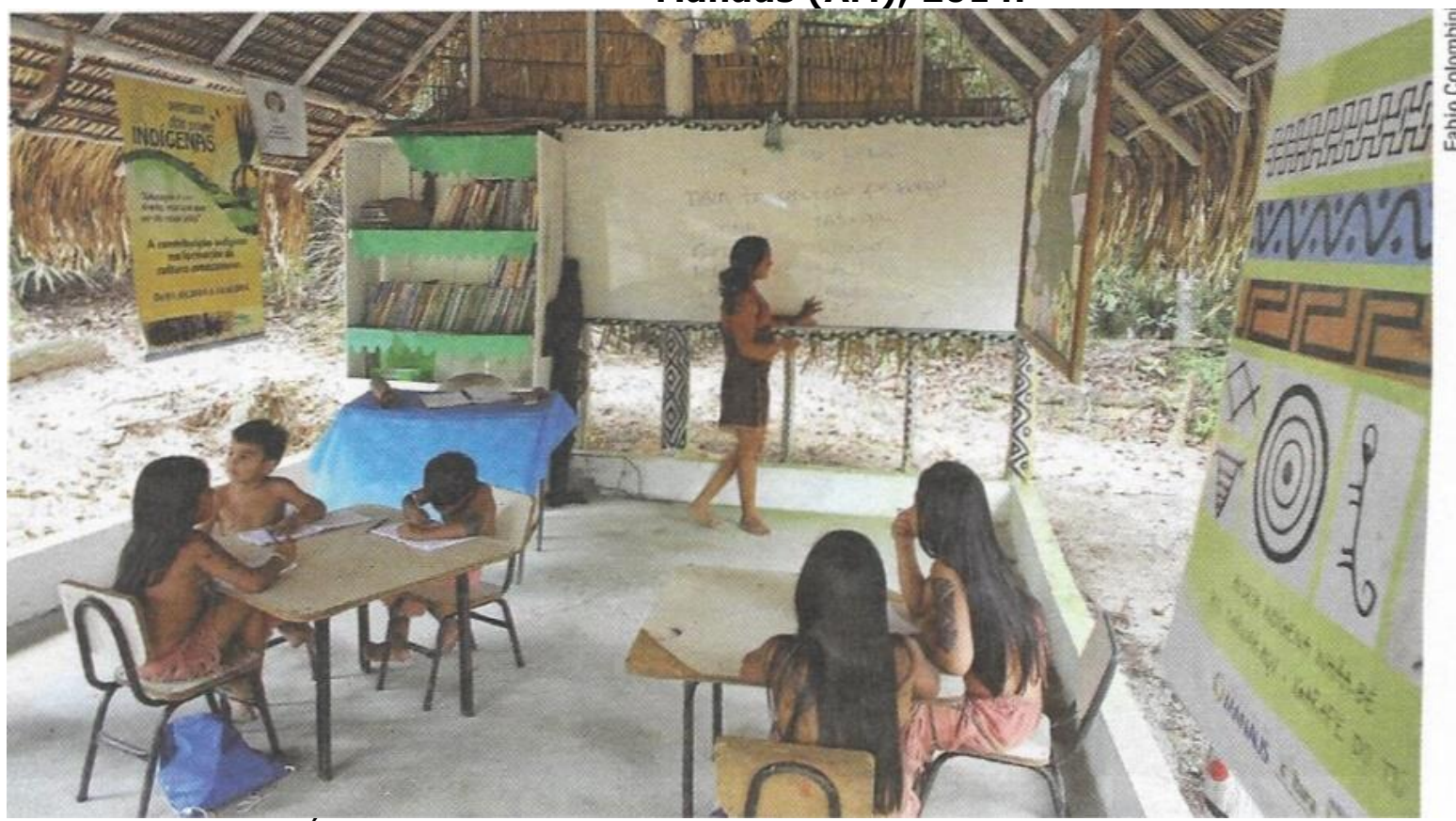

Fonte: BOULOS JÚNIOR (2016b, p. 28).

Com estrutura de madeira e palhas, sem paredes, discentes e professora sem fardamento padrão, essa é a sala de aula indígena que a maioria dos discentes das escolas públicas do Brasil irá vislumbrar por meio da coletânea em análise. Se a fotografia não tivesse legenda, somente um olhar minucioso notaria que os integrantes dela são povos indígenas. De acordo com Burke (2004), as 
imagens ajudam a compreender o cotidiano, e ao que parece, é só mais um dia de aula em uma aldeia/comunidade indígena.

É preciso considerar que, embora a professora não esteja "caracterizada" como "índia", ela é, e estar com adornos indígenas também pode ser uma marca de determinada aldeia/comunidade indígena, independente do tempo e espaço, não negamos isso. Porém, em uma sociedade globalizada, como afirma Hall (2006), a dinâmica das identidades flutua de acordo com os locais que vivenciamos e as situações na qual estamos inseridos. $\mathrm{Na}$ tribo/comunidade/cidade, talvez a professora não precise usar cocar, pintar-se ou outros adornos, mas em caso de visitas que legitimam tais sujeitos como "índios", uma caracterização se fará necessária, pois, infelizmente, a sociedade em geral ainda somente reconhece a índia e o índio que se caracteriza como "índio".

Para Hall (2006), nós somos também aquilo que imaginamos ser vistos pelos outros. Corroborando com Burke (2004), "A imagem material ou literal é uma boa evidência da "imagem" mental ou metafórica do eu ou dos outros" (BURKE, 2004, p. 37). Tomando como base esse modo de perceber a identidade, a forma que se enxerga o que é ser índia e índio é uma das facetas da identidade desse sujeito que aparece em contextos específicos. Nesse sentido, presumimos que atribuir e veicular identidade são formas de exercer poder sobre o outro, e a índia e o índio são sabedores disso e usam dessa construção identitária para exigir e conseguir direitos. Assim, "Dentro de nós há identidades contraditórias, empurrando em diferentes direções, de tal modo que nossas identificações estão sendo continuamente deslocadas." (HALL, 2006, p. 12). De acordo com o contexto e local, a índia e o índio assumem uma identidade como estratégia de sobrevivência, de existir e resistir a partir das condições sociais que thes são impostas.

Acreditamos que, por exemplo no caso da fotografias 2, na qual indígenas de diversas etnias reúnem-se caracterizados em frente ao Congresso de Brasília a fim de reivindicar direitos, possivelmente não aconteça de a índia ou índio utilizarem tais adornos em seu local de vivência - seja comunidade, tribo, cidade - mas naquela situação fez-se necessário, pois é uma forma de legitimar para o 
outro que eles pertencem à etnia indígena, visto que no imaginário brasileiro, os povos indígenas foram construídos e perpetuados de tal forma. Hall (2006), aponta que:

As sociedades da modernidade tardia [...] são caracterizadas pela "diferença"; elas são atravessadas por diferentes divisões e antagonismos sociais que produzem uma variedade de diferentes "posições de sujeito" - isto é, identidades - para os indivíduos. Se tais sociedades não se desintegram totalmente não é porque elas são unificadas, mas porque seus diferentes elementos e identidades podem, sob certas circunstâncias, ser conjuntamente articulados (HALL, 2006, p. 17).

No ato de articular as identidades, cada sujeito possui um papel reconhecido socialmente, e qualquer mudança de padrão causa o não reconhecimento do indivíduo como pertencente àquela sociedade. Assim:

O índio "ideal" deve ser forte, bonito, deve andar nu, não pode falar português, não deve gostar de óculos escuros, nem beber Coca-Cola. Deve, ainda ter lindos dentes, andar com o corpo pintado e enfeitar-se com penas. Esse é o "índio de verdade". Saindo desse padrão imaginário, criado muito distante de toda a complexidade de inúmeras situações a que são submetidos os povos indígenas brasileiros, os índios conhecidos não são "índios de verdade", ou então são "índios civilizados", "índios aculturados" (SILVA, 2014, p. 6).

Percebemos, pois, que as imagens dos povos indígenas no livro didático não os reconhecem em sua complexidade; sobressalta-se os elementos da cultura que considera o "índio genuíno", sem interferências de outras culturas, como aquele elemento formador da nação brasileira. Para Hall (2006), "No mundo moderno, as culturas nacionais em que nascemos se constituem em uma das principais fontes de identidade cultural." (HALL, 2006, p. 47). Conforme Burke (2004), "O nacionalismo é relativamente fácil de ser expresso em imagens [...]." (BURKE, 2004, p. 80).

Anderson (1989) salienta nação como uma comunidade política imaginada, limitada e soberana; comunidade porque projetava 0 sentimento de "companheirismo profundo e horizontal" entre seus pares; imaginada, uma vez que não seria possível conhecer todas as pessoas que partilham desse 
sentimento de comunhão; limitada em vista de ter fronteiras finitas e soberanas, em virtude da terminologia conceitual de nação ser instituída em época do Iluminismo e das revoluções do contexto do século XVIII, as quais destituíam o reino divinamente estabelecido (ANDERSON, 1989, p. 15-16).

O "índio" seria aquele que deu origem ao Brasil, o elemento essencial da nacionalidade, por isso estaria sempre imutável. É o mito fundacional brasileiro que, para nós, não tem por base uma história, mas sim um sujeito. Para Choppin (2004), o livro didático possibilita a "construção das identidades nacionais ou do processo de sua preservação." (CHOPPIN, 2004, p. 555), alimentando a identidade, nacionalidade, cultura e ideologia. A índia e o índio não nasceram "índio"; eles foram construídos historicamente e culturalmente, e o livro didático ajuda a erigir e propagar uma faceta dessa identidade.

As iconografias dos povos indígenas na coletânea em análise projetam o presente de volta ao passado e caracterizam a nação brasileira em sua formação essencial; porém, Hall (2006) afirma que as nações modernas são todas compostas por um hibridismo cultural. Se as identidades possuem um hibridismo, por que o livro didático ainda retrata a índia e o índio como pertencentes às coisas da terra, preservando uma identidade verdadeira e, supostamente, original? Conjecturamos haver a perpetuação de um mito nacional e o não reconhecimento de lutas de indígenas. Todavia, isso são questões que merecem um tratamento específico em pesquisas futuras.

\section{Considerações finais}

"Toda imagem conta uma história" (BURKE, 2004, p. 175). Ao tratar da imagem da índia e do índio no Brasil, a coletânea História, Sociedade \& Cidadania, de Alfredo Boulos Júnior (2016a, 2016b, 2016c), apresenta este sujeito, por excelência, nas dobras e final das páginas, à margem da posição central na obra. A índia está relacionada às atividades do lar, o índio é representado como cacique, guerreiro, construtor. A natureza nova consiste quando o indígena aparece em um tópico que versa a respeito da Constituição de 
1988, visto que em materiais didáticos anteriores a sua apresentação se limitava ao passado histórico (GRUPIONI, 1995).

"As imagens dão acesso não ao mundo social diretamente, mas sim a visões contemporâneas daquele mundo [...]" (BURKE, 2004, p. 236). Percebemos que em todas as imagens desta coletânea, exceto uma, a índia e o índio são representados de cocar, sem vestimentas nos membros superiores e corpo pintado. Esses são os elementos utilizados para reconhecer o índio ou a índia. Assim, "O livro didático não é um simples espelho: ele modifica a realidade para educar as novas gerações [...]" (CHOPPIN, 2004, p. 557). Nesse contexto, as imagens são reduzidas genericamente à categoria de "índios", como se todas as etnias fossem iguais e partilhassem da mesma cultura.

Apresenta-se uma pureza cultural indígena que não permite vislumbrar a mistura das culturas a partir dos contatos com outros povos ao caminhar do tempo. Portanto, na coleção História, Sociedade \& Cidadania, as iconografias dos povos indígenas no livro didático não os reconhecem em sua complexidade, sobressaltando-se os elementos identitários que consideram o "índio genuíno", sem interferências de outras culturas, como o formador da nação brasileira, construindo e preservando uma identidade, nacionalidade, cultura e ideologia.

De acordo com Hall (2006), as culturas nacionais são as principais fontes de identidade que podem ser expressas em imagens (BURKE, 2004). O índio original seria aquele que deu origem ao Brasil, o elemento essencial da nacionalidade, por isso estaria sempre imutável. É o mito fundacional brasileiro que não tem por base uma história, mas sim um sujeito. Para Choppin (2004), o livro didático possibilita a "construção das identidades nacionais ou do processo de sua preservação." (CHOPPIN, 2004, p. 555), alimentando a identidade, nacionalidade, cultura e ideologia. A índia e o índio não nasceram "índio", eles foram construídos historicamente e socialmente, e o livro didático ajuda a erigir e propagar uma faceta da identidade indígena. No presente texto fazer-se uma breve análise das imagens a respeito dos povos indígenas no livro didático; outras interpretações, pesquisas e indagações se fazem necessárias. 


\section{Referências}

ANDERSON, Benedict. As origens da consciência nacional. In: ANDERSON, Benedict. Nação e consciência nacional. São Paulo: Ática, 1989. p. 46-56. Disponível em: https://pt.scribd.com/doc/75948005/Nacao-e-ConscienciaNacional-Atica-ANDERSON-B. Acesso em: 13 abr. 2018.

BELO, André. História \& leitura. Belo Horizonte: Autêntica, 2002.

BITTENCOURT, Circe. Livro didático e saber escolar (1810-1910). Belo Horizonte: Autêntica Editora, 2008.

BOULOS JÚNIOR, Alfredo. História, sociedade \& cidadania: $1^{\circ}$ ano do ensino médio. 2. ed. São Paulo: FTD, 2016a.

BOULOS JÚNIOR, Alfredo. História, sociedade \& cidadania: $2^{\circ}$ ano do ensino médio. 2. ed. São Paulo: FTD, 2016b.

BOULOS JÚNIOR, Alfredo. História, sociedade \& cidadania: $3^{\circ}$ ano do ensino médio. 2. ed. São Paulo: FTD, 2016c.

BRASIL. Lei no 11.645, de 10 de março de 2008. Altera a Lei n. 9.394, de 20 de dezembro de 1996, modificada pela Lei no. 10.639, de 9 de janeiro de 2003, que estabelece as diretrizes e bases da educação nacional, para incluir no currículo oficial da rede de ensino a obrigatoriedade a temática "História e Cultura AfroBrasileira, Africana e Indígena". Brasília, Presidência da República, 2008.

BRASIL. Ministério da Educação. Edital de convocação para o processo de inscrição e avaliação de obras didáticas para o programa nacional do livro didático PNLD 2018. Brasília: MEC, 2015.

BURKE, Peter. Testemunha ocular: história e imagem. Bauru, SP: EDUSC, 2004.

CAMINHA, Pero Vaz. A carta de Pero Vaz de Caminha. Biblioteca Nacional: RJ, Disponível

em: http://objdigital.bn.br/Acervo_Digital/Livros_eletronicos/carta.pdf, acesso em

28/01/2020.

CASSIANO, Célia Cristina de Figueiredo. O mercado do livro didático no Brasil: da criação do Programa Nacional do Livro Didático (PNLD) à entrada do capital internacional espanhol (1985-2007). 2007. 252 f. Tese (Doutorado em Educação) - Pontifícia Universidade Católica, São Paulo, 2007.

CHOPPIN, Alain. História dos livros e das edições didáticas: sobre o estado da arte. Educação e Pesquisa, São Paulo, v. 30, n. 3, p. 549-566, set./dez. 2004. 
CUNHA, Manuela Carneiro. Política indigenista no século XIX. In: CUNHA, Manuela Carneiro (org.). História dos índios no Brasil. São Paulo: Companhia das Letras: Secretaria Municipal de Cultura: FAPESP, 1992. P. 131-154.

GRUPIONI, Luís Donisete Benzi. Livros didáticos e fontes de informações sobre as sociedades indígenas no Brasil. In: SILVA, Aracy Lopes da; GRUPIONI, Luís Donizete Benzi (org.). A temática indígena na escola: novos subsídios para professores de $1^{\circ}$ e $2^{\circ}$ graus. Brasília: MEC: UNESCO, 1995. p. 481-526.

HALL, Stuart. A identidade cultural na pós-modernidade. 11. ed. Rio de Janeiro: DP\&A, 2006.

IBGE. Indígenas: gráficos e tabelas. 2018. Disponível em: https://indigenas.ibge.gov.br/graficos-e-tabelas-2.html. Acesso em: 13 abr. 2018.

JOHNSEN, Egil Borre. Libros de texto en el calidoscópio: estúdio crítico de la literatura y la investigación sobre los textos escolares. Barcelona: Ediciones Pomares, 1996.

LIBÂNEO, José Carlos. Didática. Campinas: Ed. Papirus, 2006.

MARTINS, Daniel Valério Martins. Comunidade indígena Jenipapó-Kanidé: o processo de aculturação através da educação multicultural e diferenciada utilizada como ferramenta para o desenvolvimento. 2012. 106 f. Dissertação (Mestrado Interuniversitário em Antropologia Ibero-americana) - Universidade de Salamanca, Salamanca, España, 2012.

SACRISTÁN, Gimeno; GÓMEZ, Péres. Compreender e transformar o ensino. $4^{\circ}$ ed. São Paulo: Artmed, 1998.

SILVA, Phábio Rocha da. (In)visibilidade indígena no livro didático de história do ensino médio. In: ENCONTRO DE HISTÓRIA DA ANPUH-RIO: SABERES E PRÁTICAS CIENTÍFICAS. 2014, RIO DE JANEIRO. Anais [...]. Rio de Janeiro: Anpuh-Rio, 2014. p. 1-15. 